Derecho y Sociedad Revista del programa de Derecho

Vol. 1 MMXVI, $\mathrm{N}^{\circ} 1$

Luís David Sánchez Mangones ${ }^{1}$

p. $56-71$

Jorge Luís Suarez Hernández ${ }^{2}$

7201004

Sociología Jurídica

Universidad de Córdoba

Junio $14-2016$

\title{
TENSIÓN ENTRE REGULACIÓN - EMANCIPACIÓN: UN ANÁLISIS SOCIOJURÍDICO A LOS ACUERDOS DE PAZ DE LA HABANA Y SU BLINDAJE LEGAL DESDE LA PERSPECTIVA DE BOAVENTURA SANTOS
}

\section{RESUMEN}

La finalidad de este escrito es realizar un análisis sociojurídico a los Diálogos de paz realizados en la Habana-Cuba desde la perspectiva de Boaventura de Sousa Santos, para lo cual se toma como referente los comunicados y borradores oficiales de los Acuerdos de la mesa de diálogos, y a partir de éstos determinar si la naturaleza de dichos Diálogos se ubica temporalmente en la modernidad o posmodernidad jurídica.

\section{Palabras Claves.}

Regulación, Emancipación, Sociojurídico, Modernidad, Posmodernidad, Diálogos de paz, Derecho.

\section{SUMMARY}

The purpose of this article is to accomplish an analysis sociojurídico to the Dialogues of peace accomplished in the Habana Cuba from Boaventura's perspective of Sousa Santos, the one that you take like referent communications and official erasers of the Agreements of the

\footnotetext{
${ }^{1}$ Ingeniero de Sistemas. Estudiante del programa de Derecho de la Universidad de Córdoba

${ }^{2}$ Estudiante del programa de Derecho de la Universidad de Córdoba

Derecho y Sociedad|2016, Volumen1| U1| Sección 1| (15-06-2016) Versión =1
} 
table of dialogues, and as from these determining if the nature of the aforementioned Dialogues is located temporarily in modernity or juridical postmodernism.

Key words.

Regulation, Emancipación, Sociojurídico, Modernidad, Posmodernidad, Diálogos of peace, Derecho.

\section{DESARROLLO}

Los conceptos de regulación y emancipación empleados por Boaventura en su obra Sociología jurídica crítica para un nuevo sentido común en el derecho (2009), constituyen los conceptos que impulsan un nuevo sentido común del Derecho, precisamente, porque a partir de este, la modernidad -según su criterio ya superada- hace emerger la necesidad de una posmodernidad de oposición.

Boaventura señala que en las sociedades de la edad media, llena de problemas y conflictos de múltiples factores, se inicia el proyecto conocido como Modernidad, "prometiendo y abanderando el camino directo hacia la igualdad, la paz, fraternidad, libertad, etc. Tales promesas fueron abarcadas como ideales con potencial emancipatorio, que regulados hacia la sociedad a través del derecho, ampliarían la discrepancia entre la experiencia y las expectativas sociales" (2009, p. 37).

"La regulación moderna es el conjunto de normas, instituciones y prácticas que garantiza la estabilidad de las expectativas", mostrando que esto "lo hace al establecer una relación políticamente tolerable entre las experiencias presentes, por una parte, y las expectativas sobre el futuro, por la otra." (Ibíd, p. 37). Así mismo, expresa que "la 
emancipación moderna es el conjunto de aspiraciones y prácticas oposicionales, dirigidas a aumentar la discrepancia entre experiencias y expectativas, poniendo en duda el statu quo, esto es, las instituciones que constituyen el nexo político existente entre experiencias y expectativas" (Id, p. 37). Puntualizando que esto "lo hace al confrontar y deslegitimar las normas, instituciones y prácticas que garantizan la estabilidad de las expectativas -esto es, confrontando la regulación moderna-“(Id, p. 37).

De tal manera, que la tensión entre regulación y emancipación sería el factor determinante para alcanzar los fines que abanderó el proyecto de la modernidad. Sin embargo, la tensión entre estos pilares -regulación $\mathrm{v}_{\mathrm{s}}$ emancipación-, los llevo a una crisis que facilito el colapso de uno sobre el otro. Resultado obtenido por los modos de operación que tuvo el proyecto de la modernidad, en consecuencia, sin la tensión de estos pilares que fundamentarían y garantizarían el triunfo propuesto, las promesas resultaron falsas o incumplidas, de hecho, se verifican errores como el haber dado una prioridad a las ciencias y la tecnología como fuente vital (y casi que única) para brindar las soluciones y hacer realidad de tales promesas, evidenciando luego que el uso desmedido tecnológico y la cientifización generalizada (incluye al derecho), de muchas maneras indujo a que las promesas que se plantearon se vieran imposibles de cumplir, inclusive, aunque algunas problemáticas fueran superadas de cierto modo, volvían a surgir desde una nueva fuente (producto del modo de operación usado para solucionar las problemáticas anteriormente superadas).

Por ejemplo, los problemas de salud en una población por falta de avances médicos e infraestructura: según el planteamiento de la modernidad, se propone la solución con la Derecho y Sociedad|2016, Volumen1| U1| Sección 1| (15-06-2016) Versión =1 
construcción de centros médicos y el acercamiento de la tecnología de la salud a las comunidades; más sin embargo, ante la carrera por acelerar los trabajos científicos y de la ciencia (en parte buscando soluciones médicas), se condena al medio ambiente hasta el punto que afecta gravemente la salud no sólo de aquellas comunidades que carecían de infraestructura y avances de medicina, sino también de otras que no estaban en el foco inicial, extendiendo el problema que se buscaba resolver (solucionadas la necesidad de avances médicos e infraestructura; pero como consecuencia se afecta la salud de más comunidades a causa de la degradación ambiental), esto, por emplear los medios para la “solución” de forma desmedida.

"Estas contradicciones se explican por la ruptura del equilibrio dinámico entre los dos pilares fundamentales de la modernidad -regulación - emancipación-, del que ha resultado la potestad dominante del principio regulativo, autoerigido hegemónico" (Ibíd, 2009, p. 3031). En donde, uno de los componentes de la regulación se apoderó del pilar completamente (mercado) y absorbió la característica cognitivo-experimental de la emancipación para sus fines, en definitiva, no existió en la modernidad un desenvolvimiento pleno de ninguno de los dos pilares, más bien sólo existió el dominio de un elemento regulativo.

Bajo estas circunstancias nace la posmodernidad de oposición, busca abordar el Derecho ya no sólo como el factor puro, que funcionaba con indiferencia a la sociedad, sino todo lo contrario, planteando el vínculo directo y la relación inseparable que ha tenido, tiene y tendrá el derecho como elemento impuro, rosado de lo social y permeado por intereses colectivos. Es de este modo que se genera un nuevo sentido común para el derecho, un nuevo 
sentido capaz de devolverle su potencial emancipatorio a plenitud y revitalizar una completa tensión entre los pilares señalados en la modernidad.

\section{ACUERDOS DE PAZ EN LA MESA DE CONVERSACIONES EN LA HABANA-}

\section{CUBA.}

Una vez sintetizado el planteamiento de Boaventura Santos en relación a los pilares de -regulación $\mathrm{v}_{\mathrm{s}}$ emancipación-, en donde el derecho adquiriría su potencial de emancipación y de rol social con incidencia transformadora, procederemos a contextualizar este planteamiento a la luz del "Acuerdo General para la terminación del conflicto y la construcción de una paz estable y duradera”. Escenario que les permite a los delegados del Gobierno de la República de Colombia y las Fuerzas Armadas Revolucionarias de ColombiaEjército del Pueblo (FARC-EP); reunirse con la decisión mutua de poner fin al conflicto como condición esencial para la construcción de la paz estable y duradera; y atendiendo el clamor de la población por la paz, y reconociendo la necesidad de establecer la Paz en Colombia, acordaron:

- Iniciar conversaciones directas e ininterrumpidas sobre los puntos de la

- Agenda aquí establecida, con el fin de alcanzar un Acuerdo Final para la terminación del conflicto que contribuya a la construcción de la paz estable y duradera.

- Establecer una Mesa de Conversaciones que se instalará públicamente en Oslo, Noruega, dentro de los primeros 15 días del mes de octubre de 2012, Y cuya sede principal será La Habana, Cuba. La Mesa podrá hacer reuniones en otros países.

- Garantizar la efectividad del proceso y concluir el trabajo sobre los puntos de la Agenda de manera expedita y en el menor tiempo posible, para cumplir con las expectativas de la sociedad sobre un pronto acuerdo. En todo caso, la duración estará sujeta a evaluaciones periódicas de los avances. 
- Desarrollar las conversaciones con el apoyo de los gobiernos de Cuba y Noruega como garantes, y los gobiernos de Venezuela y Chile como acompañantes. De acuerdo con las necesidades del proceso, se podrá de común acuerdo invitar a otros.

La siguiente Agenda:

1. Política de desarrollo agrario integral

2. Participación política

3. Fin del conflicto

4. Solución al problema de las drogas ilícitas

5. Víctimas

\section{LAS GUERRAS Y CONFLICTOS ARMADOS DESDE EL ENFOQUE DE LA MODERNIDAD}

Vistas desde el enfoque de la modernidad, las guerras y conflictos internos armados deben ser enfrentados con los instrumentos centrales para la defensa del modelo económico existente, empleando tecnología y armas como la alternativa más viable para restringir de manera definitiva los ideales y propósitos de oposición. Esto se presenta por el carácter cognitivo-instrumental que se adquiere de la emancipación y el principio de Mercado que se superpone de la regulación, absorbiendo la emancipación pura y plena que pueda aplicarse sobre sí.

Visto de este modo, poner fin a guerras o conflictos internos cuyo objetivo sea cambiar o ajustar un modelo económico de manera consensuada, a través de mecanismos en los que se deba sacrificar ciertos espacios de ambos esquemas e ideologías para juntarlas y regularlas en la práctica social, resultaría algo inconcebible para la modernidad, teniendo en cuenta su despliegue a lo largo de la historia. Por razones como estas, se deben realizar ciertos cambios en cuanto a la idea de la política, es lo que plantea Boaventura. Para este autor, la tesis de la modernidad falló en dar solución a los problemas y al pretender sostener esos pilares en tensión con un modelo político equívoco y autodefensivo no dispuesto al cambio y a la transformación.

Derecho y Sociedad|2016, Volumen1| U1| Sección 1| (15-06-2016) Versión =1 
Un ejemplo, serían situaciones como el conflicto armado interno profundamente arraigado entre el Estado Colombiano y las Fuerzas Armadas Revolucionarias de Colombia - FARC EP, las cuales siendo foco de atención han sido combatidas con acciones para contrarrestarlas, centradas y cerradas en la única alternativa del enfrentamiento armado, sin disposición a ceder espacios políticos y económicos ante los ideales que plantea la oposición.

Ha sido así como en el transcurso de este conflicto la problemática inicial ha ido acrecentándose, cobrando miles de vidas humanas de compatriotas tanto guerrilleros como policías y militares, ni qué hablar de los civiles y líderes comunitarios que han caído en medio del combate, los desplazados y los privados de la libertad, quienes han sido mutilados y las familias que han sido destrozadas a causa de esta guerra, comunidades enteras han sido transformadas y se les ha desaparecido la tradición y culturas autóctonas, la propiedad privada del más débil (campesino) ha sido despojada (viendo entonces que la propiedad privada no es propensa de ser amenazada por los diálogos de Paz, sino que ha sido desaparecida para muchas familias de campesinos colombianos, quienes carentes de poder político o económico no han podido defenderse, a diferencia de la clase dominante cuando sienten riesgo de disminuir sus altas ganancias y posesiones).

El agro colombiano en abandono, la violencia de otros grupos al margen de la Ley se impone en muchos territorios ante la ocupación de gran fracción de las autoridades para la defensa del Estado frente a un solo conflicto, estas situaciones surten efectos que se han extendido, llevándose consigo muchos baluartes nacionales tanto materiales como inmateriales. También afecta una inversión nacional desmesurada hacia un conflicto en comparación con la poca fracción destinada a la educación, la pérdida de la esperanza en gran parte de la población y muchas más secuelas producidas por la vía moderna para enfrentar esta problemática.

Tantos años de combate sólo se han convertido en más problemas, por lo tanto, desde el comienzo de este conflicto interno, es posible afirmar que las promesas de la Paz, la Libertad, la Solidaridad Social y la Fraternidad, han sido falsas conforme a la idea de la modernidad y a los modos de poner fin a tal problemática. 
En relación a lo plateado, Boaventura Santos sostiene que "el éxito de la emancipación estaría, por tanto, en una nueva relación política -transitoria-, entre la experiencia y la expectativa, el consenso y la resignación y la esperanza y la desesperanza. Sin embargo, sus contradicciones provocaron el fracaso del ideal moderno y el incumplimiento de sus grandes promesas: la igualdad, la libertad, la paz y el dominio de la naturaleza". (Santos, 2009, p. 36-42).

\section{ALTERNATIVA POSMODERNA: Diálogos de Paz}

Sobre la base de las consideraciones anteriores, puede afirmarse que alternativas como los diálogos de paz, reflejan una idea de emancipación apropiada para ejemplificar lo propuesto por Boaventura, haciendo fuerza a su tesis de la posmodernidad de oposición, que junto a las experiencias sociales (regulación) lideradas en honor a esta nueva propuesta, se deslindaría del limitante impuesto por el principio de Mercado que absorbía únicamente el carácter cognitivo-instrumental de la emancipación.

En este caso, se busca ampliarlos en su expresión natural y perfecta, de manera que al principio de Mercado de la regulación se le sumarían: la comunidad y el estado (quienes en la práctica del proyecto de la Modernidad habían sido aplastados), por otro lado la emancipación, a la vez de recuperar su autonomía, también puede disolver sus tres dimensiones plenamente en la experiencia, ya no sólo lo cognitivo-instrumental a favor del mercado sino que en su plenitud: La racionalidad moral-práctica del derecho, la racionalidad cognitivo experimental de la ciencia y la técnica, y la racionalidad estético expresiva de las artes y la literatura. Adaptadas a ver en las promesas que tuvo la modernidad, soluciones y no problemas, que con un nuevo modo de operación darán paso al cumplimiento de las 
promesas que incumplió la modernidad. Es en este ámbito donde difiere el posmodernismo de oposición que plantea Boaventura, con el Posmodernismo celebratorio ${ }^{3}$.

Concluyendo la idea del ejemplo anterior, en que tantos años de intentos modernos para finalizar el conflicto contra las FARC-EP han sido en vano, en palabras de Boaventura "parece, pues, que afrontamos problemas modernos para los que no hay soluciones modernas". (2003a, p. 30). Para un posmodernismo celebratorio esto significaría que probablemente no haya siquiera problemas modernos o unas tales promesas de la modernidad, y lo que existe, entonces, deba ser aceptado y elogiado (De tal forma que el posmodernismo celebratorio puede ser considerado simplemente una nueva versión del modernismo). "Esta es una postura que no reconoce la transición de paradigmas, ni como hecho ni como posibilidad". (Santos, 2009, p. 42-43) Para la consideración inquietante o de oposición, es posible y necesario pensar la regulación y la emancipación social más allá de los límites impuestos por el paradigma moderno, asumiendo "que existe una disyunción entre los problemas de la modernidad y las posibles soluciones de la posmodernidad, la cual debe ser convertida en punto de partida para afrontar los desafíos derivados del intento de construir una teoría crítica." (Santos, 2006, p. 25).

\footnotetext{
${ }^{3}$ De esta manera llama Boaventura al posmodernismo que plantea que los problemas modernos tienen soluciones modernas y, por lo tanto, no se justifica hablar de una transición de paradigmas. Hay grandes variaciones dentro de la posición modernista. Por una parte, están quienes piensan que la modernidad occidental incluye muchos tipos de modernidades, y que el problema reside en la versión de la modernidad que terminó dominando; así, las nuevas soluciones modernas para los nuevos problemas modernos deben buscarse en las otras versiones de la modernidad.
} 
Comprendiendo la nueva propuesta de posmodernidad de Boaventura, la superposición del principio de mercado en cuanto a la regulación será superada, porque será de igual influencia el principio de comunidad y las ideas que este incluye, como participación, solidaridad, autogobierno, obteniendo sus aportes para temas importantes como son la convivencia, la salud, el sector privado sin ánimo de lucro y la Paz. Al remplazar la subjetividad social en detrimento de la ciudadanía, con las dimensiones completas de una emancipación posmoderna se podrán combatir temas de inconveniencia colectiva como el privatismo, de-socialización y el individualismo impostor; que acoplados a la vertiente productivista, sólo han servido para volcar a las comunidades hacia una idea consumista, expresando un idealismo fundado en objetos o imágenes virtuales que se enfatizan en persuadir para orientar más por el tener, que por el "ser" como característica de la personalidad: lo que se conoce como subjetivismo objetístico.

Por todo esto, se infiere que temas como la finalización de conflictos por vías de diálogos, con defensa estatal política que reconoce la importancia y el valor social que tienen nuevas alternativas que van más allá de instrumentalización para defensa del orden existente (sin posibilidad de cambio), se enmarca en el tiempo de posmodernidad oposicional planteada por Boaventura.

COMUNICADO CONJUNTO \# 69. La Habana, Cuba. 12 de mayo de 2016: Desde La Posmodernidad.

De acuerdo con los razonamientos que se han realizado, el comunicado conjunto \# 69 emitido por las delegaciones del Gobierno de Colombia y de las FARC-EP, resultó ser un tema de gran impacto en la comunidad nacional, generando grandes debates y posiciones con respecto a él. El blindaje o soporte legal que se planteó en el comunicado con relación a los 
acuerdos que se concluyan en la Habana, consecutivamente sean aprobados por el pueblo colombiano y cumplidas las labores legislativas prometidas, consiste en otorgar un nivel Constitucional a lo que se establezca en dicho proceso.

Para comprender -desde los planteamientos de Boaventura- este tipo de situaciones, es necesario precisar la posmodernidad que como pilar de regulación podría confluir con movimientos emancipatorios poderosos como los ecológicos, feministas, pacifistas, antirracistas, consumidores, autoayuda o estudiantiles, como nuevos protagonistas en un renovado campo de innovación y transformación social, como críticos de la regulación social capitalista y de la emancipación social socialista (de forma objetiva y utilitarista: dejando de lado la barrera mental que genera una imposibilidad para admitid y reconocer el valor o reconocimiento legal justo para los ideales de oposición).

Obteniendo como resultado mecanismos de defensa que intermedien y protejan el interés común contra las formas de opresión que surjan más allá de las relaciones de producción (mercado), como son la guerra, los conflictos, la polución, el machismo, el racismo, el productivismo, el consumismo; esto, gestionando un nuevo paradigma social en el que pierda la primordial importancia la riqueza y el bienestar material, dando más orientación al cambio cultural y la calidad de vida, donde la emancipación tiene como objetivo transformar lo cotidiano aquí y ahora y no a diez o más años como lo propone la racionalidad de la planeación estratégica moderna, la emancipación comienza hoy o no comienza nunca, tal como lo plantea Boaventura.

En consecuencia con lo anterior, es posible determinar que la alternativa de posmodernidad de oposición, cobija rutas conceptuales en su teoría para sucesos como el de la Constitucionalidad y el blindaje legal para los acuerdos de Paz, de hecho, de eso se trata su planteamiento, adentrándose en un debate acerca de subjetividad y ciudadanía, visto desde el marco de la sociedad civil más que en el marco del estado fríamente comedido para un calculado trato entre los sindicatos y partidos tradicionales (con ideales e intereses modernos). 
En este punto los Nuevos movimientos sociales lucharían no por una emancipación política o económica (exclusivamente), sino también personal, social y cultural, con grupos sociales como protagonistas y con intereses comunes en potencia.

De tal manera, que las formas de opresión y de exclusión contra las cuales luchan no pueden ser abolidas de forma violenta (con los modos modernos ya mencionados), o con la mera concesión de derechos abstractos y universales típicos de la ciudadanía individualista, tal como el caso de quienes se oponen a la Paz: Quienes se niegan a reconocer en el Derecho el concepto que ha sido demarcado en la Constitución del 91 con relación a las Leyes, donde ley es, no solo al acto formal y material del Congreso, sino que integra un universo jurídico que busca la realización axiológica de la justicia, tal como lo consagra el Preámbulo; En esta secuencia de ideas, ley es también la Constitución Política [art. 4], los tratados o convenios internacionales sobre Derechos Humanos [Art. 93]. Y los principios inherentes a la persona [art 94]. Sólo reconociendo y practicando estos fundamentos sería posible una tensión entre regulación y emancipación posmoderna sobre el modelo jurídico para el posconflicto, de lo contrario se daría continuidad al mismo paradigma moderno que cierra las alternativas cuando no son directamente benéficas al carácter cognitivo-instrumental del mercado.

Es en Fe de esto que algunos de los nuevos movimientos y luchas sociales exigen transformaciones concretas, inmediatas y locales como el cierre de empresas que violenten al medio ambiente y no utilicen la reparación de los daños causados en su momento y adecuadamente -como por ejemplo; vías terrestres sobre ciénagas o humedales, edificaciones sobre reservas ambientales, las hidroeléctricas, etc. --. Al igual que la prohibición de la publicidad violenta en televisión, la corrupción, los malos procesos democráticos, etc.

A pesar de que sigan presentes los principios de Estado y de mercado, el principio de la comunidad planteada por Rousseau, es el que tiene más potencialidades para fundar las nuevas energías emancipatorias, es aquí donde estaría la clave para la defensa de lo público y el reconocimiento legal justo de las luchas sociales para el bien común.

La obligación política horizontal entre ciudadanos, la participación y la solidaridad que vayan más allá del subjetivismo, concretas en la consecución de la voluntad general, son 
quienes pueden fundar una cultura política, una nueva calidad de vida personal y colectiva, basadas en la autonomía y en el autogobierno, en la descentralización, la democracia participativa, el cooperativismo y en la producción útil para la sociedad (en sus distintas comunidades). La politización de lo social (y no la imposición social de lo político), lo cultural, lo personal, abre un inmenso campo para el ejercicio de la ciudadanía.

Entonces Acuerdos de Paz como los que se realizan en la Habana Cuba y el blindaje propuesto en el comunicado \# 69, ya no resultarían extraños e indebidos para la población nacional colombiana, viendo casos de países como España han logrado dar tregua y finalizar conflictos internos como el del conocido grupo Euskadi Ta Askatasuna (ETA) y Nicaragua a través del fin al conflicto contra el Frente Sandinista de Liberación Nacional (FSLN), se podría ver más allá del subjetivismo objetístico que se ha impulsado, ampliando ahora las capacidades emancipatorias hasta el punto de reafirmarla como pilar y tensionarla con la regulación. Boaventura de Sousa Santos aporta a la construcción de las nuevas teorías, teniendo en cuenta lo antes expuesto: Para la teoría democrática sugiere una repolitización global de la práctica social y para el campo político crear nuevas oportunidades para ejercer nuevas formas de democracia y ciudadanía. Distingue cuatro espacios políticos estructurales:

1. El espacio de la ciudadanía

2. El doméstico

3. El de la producción

4. El mundial

En la nueva teoría de la emancipación, combatir los excesos de regulación de la modernidad, por medio de una nueva ecuación entre subjetividad, ciudadanía y emancipación, forjan un nuevo sentido común político y del Derecho, que permita revalorizar positivamente el principio de la comunidad con las ideas de igualdad, paz, autonomía y solidaridad. 
Por consiguiente, a tales planteamientos sería válido afirmar que el blindaje propuesto por la mesa de conversaciones del Proceso de Paz en la Habana-Cuba, la ruta legal (marco normativo) y el carácter constitucional otorgado a los acuerdos que se generen en tal proceso, son exactamente lo que se propone en la teoría de Boaventura, borrar los límites impuestos y permitirse imaginar otras posibilidades más allá de lo que existe, imaginar otras teorías posibles donde se prevea y sea posible comprender la diferencia del futuro.

Entonces la misión de la teoría crítica postmoderna (oposicional) consiste precisamente en eso, el Derecho para el bien común y la justicia social, empleando como método estudiar todo lo que existió tanto negativa como positivamente en la experiencia histórica de lo contemporáneo, identificando lo que permitirá precisar una mejor toma de decisiones orientada más por el bienestar general y menos por los intereses económicos subjetivistas de las dirigencias. Intento que en el caso de Colombia aparentemente había sido omitido, referentes históricos como el fin del conflicto con el M19 han sido ahogados y no han retroalimentado el deseo de finalizar conflictos por las vías del diálogo, en consonancia ha sido necesario un debate político por la Presidencia de la república lo que ha traído a una reflexión teórica-doctrinal desde el Derecho hacia este proceso.

Finalizamos afirmando que no es posible hablar de posmodernidad, ni de cambios sociales o mejoras continuas, cuando se prohíbe la práctica libre y con principios humanos de la innovación, la transformación, el avance ideológico del Derecho, sino que se superpone la ciencia adoptada a favor de la perduración de los modelos impuestos (existentes). Olvidando la emancipación del todo, absorbiéndola, sólo se adentra a las comunidades en crisis de poca Fe y la incredulidad hacia las propuestas, transitando ya no en una crisis entre 
una tensión para la Regulación emitida por la Emancipación, sino que la regulación a nivel interno sufriría rupturas, por contradicciones internas y la inseguridad ideológica que emana del promover una libertad ideológica y a la vez poner barreras y límites para la misma. 


\section{Referencias bibliograficas}

Santos, Boaventura De Sousa. (2009) Sociología jurídica crítica para un nuevo sentido común en el derecho. ILSA. Colección En clave de Sur. Bogotá.

(1998) ¿Por qué es tan difícil construir una teoría crítica? Zona abierta. (82/83). p. 219-229. Madrid.

(1998) Subjetividad, Ciudadanía y Emancipación sobre el capítulo noveno del libro De la mano de Alicia. Lo social y lo político en la postmodernidad. Siglo del Hombre Editores - Ediciones Uniandes. p. 456. Bogotá.

- (1998) Subjetividad, Ciudadanía y Emancipación. Revista Cátedra Paralela Año 1, No 1. Universidad del Rosario. Escuela de Trabajo Social. Bogotá.

Mesa de Conversaciones para la Terminación del Conflicto y la Construcción de una Paz Estable y Duradera (2012-2016) Disponible en: https://www.mesadeconversaciones.com.co/

\section{Como citar este artículo}

Sánchez-Mangones, L., Suarez H. Jorge (2016) Tensión entre REGULACIÓN EMANCIPACIÓN: Un análisis Sociojurídico a los Acuerdos de paz de la Habana y su blindaje legal desde la perspectiva de Boaventura Santos. Derecho y Sociedad. 1(1), 56-71. Universidad de Córdoba. Montería. 